\title{
Study on Service Identity and Identity Framework
}

\author{
Hwa Sun Kang, Young Hwan Pan \\ Interaction Design, Graduate School of Techno Design, Kookmin University, Seoul, 136-792
}

\begin{abstract}
Objective: Service industry has become the most important industry among various economic activities, as the percentage of service related industry in advanced nations is over $60 \%$ of their GDP and the percentage of service industry in South Korea, a traditional manufacturing nation, now takes up over $60 \%$ of the entire economy. Background: Such industry paradigm shift has changed consumers from those that simply purchased products into groups of people that evaluate the companies that manufacture products, thereby further intensifying competition among companies and increasing the importance of integrated communication between companies and consumers. However, the excessive existence of sub-identities that have been developed for integrated management of the existing corporate identities, as well as the undifferentiated general management strategies by companies are creating confusion not only for consumers but also for various corporate interest parties. In addition, service identity strategy has become the most important strategy than any other sub-identity strategies in forming corporate identity at the increased importance of corporate service in the era of service industry. However, the current domestic circumstance is that the concept of service identity has not been well established through specific related studies. Method: Accordingly, the existing academic and field studies on the corporate identity(CI), brand identity(BI) and product identity(PI) used for the communication with consumers were reviewed in this study to establish and summarize the concept of service identity(SI) that appeared at the service economization. Results: The purpose is to examine the kind of change that could be brought about by SI for the corporate integrated identity strategy developed through the existing corporate, brand \& product image in order to present a new direct in corporate identity strategy according to the industry paradigm shift through a SI centered new corporate identity framework. Conclusion: For preparing the new era of service industry, the corporate integrated identity strategy must be integrate with concept of service identity and which is essential to differential from other companies. Application: The proposed concept and framework of service identity on this paper will help to understand and clearly define why service identity is important factor of the new idea of corporate identities.
\end{abstract}

Keywords: Service identity, Cooperate identity, Brand identity, Product identity

\section{Introduction}

우리나라를 포함해 전 세계 주요국은 이미 서비스산업이 경제 활동 중 가장 중요한 산업이 되었는데 경제의 가치창출 의 원천이 제조에서 서비스로 옮겨가는 '서비스 경제화'가 가속화 되고 있는 것에는 두 가지 이유가 있다. 첫째, 서비스 업을 주로 수행하는 기업이 많아지고 있기 때문이고 둘째,
전통적 제조기업들도 부가가치를 더 확보할 수 있는 서비스 사업 쪽으로 사업 포트폴리오를 변화해가고 있기 때문이다. 이로 인해 결과적으로 경제에서 차지하는 서비스의 비중은 지속적으로 커져가고 있다(Yoon, 2011). 제조업에서 서비스 업으로의 이동은 단순히 제품을 파는 시대를 지나 기술과 서 비스에서 판가름이 나는 소비시대로 접어 들었음을 의미한 다. 이러한 소비시대에는 기업의 서비스나 제품의 브랜드 인 지도에 대한 전통적인 매체의 영향력이 감소하고 고객의 브 
랜드에 대한 경험은 중요해 지는데 연구된 기업의 아이덴티 티의 정의와는 달리 제품의 다각화와 독립적인 브랜드의 중 요성 부각으로 그 통합성을 가지지 못하고 브랜드 아이덴티 티에 대한 연구가 주를 이루며, 시각적인 부분에 초점이 맞 춰져 있다. 물론 아직도 시각적 아이덴티티가 기업 아이덴티 티를 구성하는 중요한 영역이란 사실은 변함이 없으나 서비 스산업이 빠르게 영역을 확장해 나아가는 시대의 변화에 뒤 쳐지지 않기 위해선 기업의 행하는 모든 유, 무형적 행위를 아우르는 통합된 기업 아이덴티티 전략과 구성체제의 재 정 비가 필요한 시점이 되었다.

특히 지금까지는 무형에 사멸성이 강해 측정하기 어려웠 던 서비스의 가치를 서비스측면에서 일관성 있게 전달하여 소비자에게 하나의 기업 아이덴티티로 제시할 수 있는 서비 스 아이덴티티는 기존의 기업 아이덴티티가 고려하지 않았 던 영역으로 기업 아이덴티티의 역할에 변화를 가져올 수밖 에 없는 중요한 아이덴티티 영역으로 자리잡고 있다.

이에 본 연구에서는 현재까지 국내외 학계와 실무에서 기 업이미지 구축과 소비자와의 커뮤니케이션을 위해 사용된 기업 아이덴티티(CI), 브랜드 아이덴티티(BI), 제품 아이덴
티티(PI)의 기존연구를 검토하고 이를 통해 서비스 아이덴 티티(SI)의 개념을 정립하고 구조적으로 정리하여 서비스 아이덴티티(SI)의 등장이 기존의 기업, 브랜드, 제품이미지 로 만들어낸 기업의 통합적인 아이덴티티에 어떤 역할로 자리잡을 수 있는지 알아보고자 한다. 또한 기존의 기업 아 이덴티티에 서비스 아이덴티티 중심의 새로운 기업 아이덴 티티 프레임워크를 제안하여 산업 패러다임의 변화에 따른 기업의 아이덴티티 전략에 새로운 방향성을 제시해 보고자 한다.

\section{Identity Comparison}

\subsection{Corporate identity}

아이덴티티의 사전적 의미를 살펴보면 정체성, 자기 동일 성 즉 타인과 구분되는 고유한 차별성이라고 되어 있다. 기 업에 적용된 아이덴티티는 아직까지 통일된 학문적 정의가 없는 가운데 개념적인 정의는 문헌과 실무에서 시대에 따라

Table 1. Concept of corporate identity

\begin{tabular}{|c|c|}
\hline Name & Definition of corporate identity \\
\hline $\begin{array}{l}\text { Selame \& Selame } \\
\quad 1975\end{array}$ & $\begin{array}{l}\mathrm{CI} \text { is everything that is planned and visual. It is a corporate visual statement on who \& what the company is and how } \\
\text { the company appears. }\end{array}$ \\
\hline $\begin{array}{l}\text { Margulies } \\
1977\end{array}$ & $\begin{array}{l}\text { Every type of method selected to identify itself to every interest party of the company(community, customer, employee, } \\
\text { the press, current/future shareholder, stock analyst and investor). }\end{array}$ \\
\hline Olins 1978 & $\mathrm{CI}$ is related to the external appearance of company. \\
\hline $\begin{array}{l}\text { Birkight \& Stadler } \\
\quad 1980\end{array}$ & $\begin{array}{l}\text { A method of revealing the identity of organization through the components of action, communication and symbol for } \\
\text { the internal \& external public. }\end{array}$ \\
\hline Anspach 1983 & $\begin{array}{l}\mathrm{CI} \text { is the total expression of the organization. Namely, it is the sum of elements that make the company unique. Its } \\
\text { expression that is delivered to various types of public through various media is not all that simple. }\end{array}$ \\
\hline Lee 1983 & $\mathrm{CI}$ is the "personality" and "soul" of the company. \\
\hline Topalian 1984 & $\begin{array}{l}\text { It is to clearly express what the company is about, what the company symbolizes and what the company does. CI is } \\
\text { under the control of the parent company and it is planned systematically. }\end{array}$ \\
\hline $\begin{array}{l}\text { Alert \& Whetten } \\
1985\end{array}$ & $\begin{array}{l}\text { CI is defined from an organization behavioral level that it signifies the core characteristics revealed at the essence of } \\
\text { the organization, the differentiation that makes the organization distinct, the periodic continuity of showing the } \\
\text { sameness regardless of the flow of time, etc. }\end{array}$ \\
\hline $\begin{array}{l}\text { Portugal \& Halloran } \\
\quad 1986\end{array}$ & $\begin{array}{l}\text { A total and organized expression about the company, where the company is headed and how the company is different } \\
\text { from other companies. CI is the essence of corporate communication. }\end{array}$ \\
\hline Downey 1986 1987 & $\mathrm{CI}$ is the fundamental organizational style, organization quality and the characteristic and personality of organization. \\
\hline $\begin{array}{l}\text { Kammerer } \\
1988\end{array}$ & $\begin{array}{l}\text { CI was divided into four structures. } \\
\text { 1. Financial orientation: A subsidiary maintains its separated identity without the interference from the parent company } \\
\text { 2. Organizational-oriented corporate identity: The parent company and subsidiaries share the organizational rules and the } \\
\text { culture of subsidiary is limited to the role of internal identity. } \\
\text { 3. Communication-oriented corporate identity: The fact that the subsidiary clearly belongs to the parent company is } \\
\text { clearly expressed in the ad and symbol } \\
\text { 4. Single company identity: Every action, message and symbol is conveyed in consistent totality. }\end{array}$ \\
\hline
\end{tabular}


Table 1. Concept of corporate identity (Continued)

\begin{tabular}{c|l}
\hline Name & \multicolumn{1}{c}{ Definition of corporate identity } \\
\hline $\begin{array}{c}\text { Olins } \\
1989\end{array}$ & $\begin{array}{l}\text { Upon dividing it into monolithic identity, endorsed identity and branded identity, CI was defined and explained as } \\
\text { the total image and value of a company as its products and everything related are perceived differently from that of } \\
\text { competitors, in addition to the differentiation of visual elements such as company logo or name. }\end{array}$ \\
\hline $\begin{array}{c}\text { Carls } \\
1989\end{array}$ & $\begin{array}{l}\text { CI has active or visual consistency. It is more of an attitude than a strict rule. In addition, CI program has a series of } \\
\text { compatibility than standardized image. }\end{array}$ \\
\hline $\begin{array}{c}\text { Abratt } \\
1989\end{array}$ & $\begin{array}{l}\text { As a type of visual clue(from physical/behavioral aspect), CI distinguishes a company from others and helps to } \\
\text { recognize it. This clue is used to express and symbolize the company. }\end{array}$ \\
\hline $\begin{array}{c}\text { Olins } \\
1991\end{array}$ & $\begin{array}{l}\text { Perceived corporate activities being clearly managed in a few or every way. CI can be planned into three types: who } \\
\text { are you, what are you doing, and how are you doing it }\end{array}$ \\
\hline $\begin{array}{c}\text { Balmer } \\
1994\end{array}$ & $\begin{array}{l}\text { A mix of strategy, action(culture) and communication. It is not an area of managing something but related to several } \\
\text { management areas. Organizational philosophy usually comes from ownership. }\end{array}$ \\
\hline Seonen 1998 & CI was approached as the mind, soul and voice of a company. \\
\hline $\begin{array}{c}\text { Balmer \& Seonen } \\
1999\end{array}$ & $\begin{array}{l}\text { CI was defined based on the corporate ideology \& philosophy as every activity of identifying and integrating the } \\
\text { organization through the expression of behavioral, visual and linguistic expression. }\end{array}$ \\
\hline $\begin{array}{c}\text { Melewar \& Jenkins } \\
2002\end{array}$ & $\begin{array}{l}\text { CI was analyzed centering on the 4 sub components, and summarized into communication \& visual identity, action, } \\
\text { corporate culture and market situation result. }\end{array}$ \\
\hline $\begin{array}{c}\text { Melewar, Karaosmanoglu } \\
\& \text { Paterson 2005 }\end{array}$ & $\begin{array}{l}\text { CI was explained by further expanding and classifying the CI structure into the 7 factors of corporate communication, } \\
\text { corporate design, corporate culture, action, corporate structure, business identity and corporate strategy. }\end{array}$ \\
\hline
\end{tabular}

조금씩 그 의미를 달리하고 있다. 기업 아이덴티티와 관련된 문헌을 통해 해외에서 연구된 기업 아이덴티티의 개념적 정 의들을 정리하면 위 표와 같다(Alessandri et al., 2001).

국내의 기업 아이덴티티에 대한 연구는 그 동안 브랜드의 시각적인 차별성 전략에 초점을 맞춰 진행되었지만 시대의 변화에 따라 그 범위가 점점 확대되고 있다. Choi and Kim (2000)은 기업 아이덴티티 구성요소를 제품, 서비스, 직원, 유통, 이미지 등 다섯 가지로 구성하여 제품은 물론, 조직의 구성원, 서비스까지로 기업 아이덴티티를 확대하여 평가하 였다.

Son(2003)은 마인드 아이덴티티, 행위 아이덴티티, 시각 아이덴티티, 웹 아이덴티티 4가지로 기업 아이덴티티를 설명 하였는데 마인드, 행위 아이덴티티에 기업의 철학, 가치, 구 성원의 정신 및 조직의 정책을 담아 기업 아이덴티티의 범 위를 확대 해석하였다.

시대에 따라 내려진 국내외 여러 학자들의 기업 아이덴티 티의 정의는 조금씩 다르지만 종합하여 보면 기업의 아이덴 티티는 기업의 모든 활동과 이에 관련된 이해관계자들의 관 계를 통해 형성되는 그 기업의 다양하지만 고유한 전략들로 기업의 정체성을 총체적으로 나타낼 수 있는 핵심 가치를 말 한다.

\subsection{Brand identity}

Ahn and Rhi(2010)의 브랜드 아이덴티티는 기업의 핵심
목표이자 철학인 기업 아이덴티티를 브랜드 차원에서 활용 한 것이다. 브랜드 아이덴티티는 기업이 표적고객의 마음속 에 심어주기를 원하는 바람직한 연상들로 정의되며, 제품 특 성, 브랜드 명, 심벌, 광고, 판매촉진, 이벤트, $\mathrm{PR}$ 등과 같은 모든 수단을 통합적으로 관리라는 과정을 의미한다. 브랜 드 아이덴티티도 국내외 여러 학자들에 의해 정의되고 연구 되었는데 처음 브랜드 아이덴티티란 용어는 프랑스 HEC (Hautes Etudes Commerciales) 의 마케팅 교수인 쟝 노엘 캐퍼러(Jean-Noel Kapferer)에 의해 사용되었다. 하지만 실무에서의 활발한 활용은 1996년 UC버클리의 경영학과 교수인 데이비드 아커(David A. Asker)가 브랜드 아이덴 티티 구축모델을 제안하면서 시작되었다. Asker(2002)의 Figure에서 보면 Asker는 브랜드 아이덴티티를 형성하는 요소를 브랜드 에센스, 핵심 아이덴티티, 확장 아이덴티티로 구성하였는데 브랜드 에센스는 브랜드의 핵심을 파악하는 단일개념으로 핵심, 확장 아이덴티티를 묶는 축으로 정의하 고 핵심 아이덴티티는 시간과 새로운 시장, 새로운 제품 출 시 등 모든 변화에 변함없이 표출되는 브랜드의 가치로 분 석하였다. 마지막 확장 아이덴티티는 브랜드를 알리고 관리 하는 세부요소들로 소비자들에게 브랜드의 가치와 의미를 구체적이며 가시적으로 전달하는 역할로 제품, 조직, 개인(사 람), 상징 등 4 가지로 구성하였다. 국내의 브랜드 아이덴티 티에 대한 연구를 살펴보면 Jang and Song(2006)은 제품 의 계면인 인터페이스의 일관적이면서 차별화된 시각적 아 이덴티티 구축을 통한 브랜드 아이덴티티 강화를 주장했고 


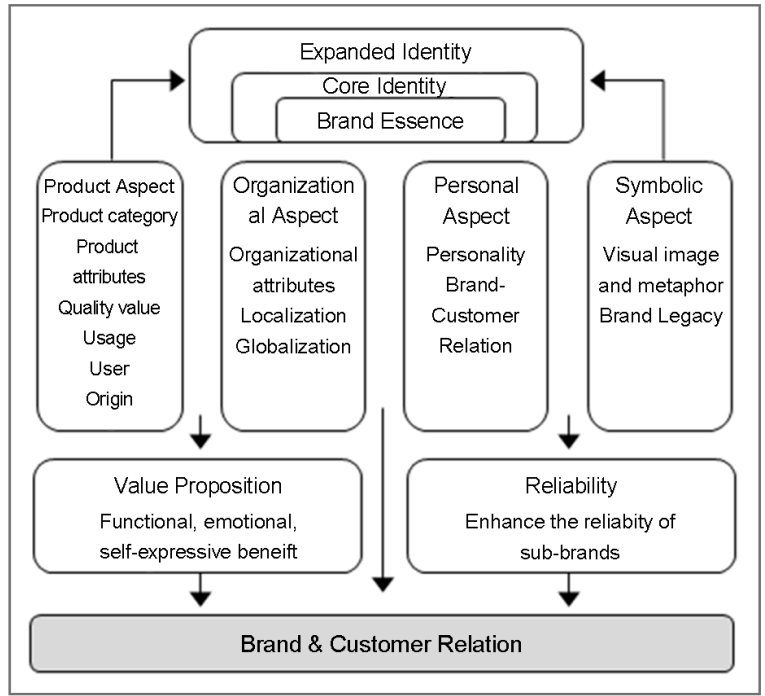

Figure 1. Brand identity planning model

Byeon(2006)은 심볼, 로고, 색상 등 시각적인 요소의 관리 전략이 기업의 철학과 브랜드와 조화를 이뤄야 성공적인 브 랜드로 판단하였다. 이처럼 국내의 브랜드 아이덴티티도 기 업 아이덴티티의 연구와 같이 시각적인 부분에 좀 더 비중을 두어 연구되고 있다.

\subsection{Product identity}

제품 아이덴티티의 개념은 기업 아이덴티티의 일환으로
기업 아이덴티티를 형성하는 여러 가지 요인들 중에서 기업 이 제품을 통해 그 기업의 이미지를 동일하게 반영하는 것을 말한다. 즉, 제품에 기업의 철학, 문화를 담는 동시에 사용에 대한 만족한 경험과 가치를 함께 전달하는 제품이미지 통합 전략이라 정의할 수 있다. 제품 아이덴티티에 대한 소비자의 경험은 제품에 대한 이미지를 형성하게 되고 이러한 이미지 들은 브랜드가 가지는 이미지, 나아가 기업이 가지는 이미지 도 결정하게 된다. 제품에 대한 이미지를 좌우하는 소비자의 경험에 대해 Seok(2011)은 제품을 사용하는 사용자의 경 험단계를 사용자가 제품을 처음 인식하고 인상을 갖는 물리 적 단계, 사용자가 제품을 본격적으로 사용하는 단계로 제품 을 사용해야만 체득할 수 있는 인터렉션 단계, 제품 사용 후 사용자가 느끼는 전반적인 경험을 묶은 개념적 단계로 나 누어 설명하였다. 이런 사용자의 경험단계를 거친 후 소비자 의 인식 속에 남아있는 제품과 기업에 대한 총체적인 평가는 대부분 추상적이고 무형적인데 포장, 디자인, 상표, 가격 등 의 속성들은 이런 무형의 품질을 추론하기 위한 정보를 제 공하며 이는 기업의 이미지 형성에도 큰 기여를 한다. Lee (1998)은 '기업의 제품이미지 통합관리에 관한 연구에서 무 형(기업)과 제품(유형)을 함께 관리할 수 있는 제품 아이덴 티티 통합요소를 아래와 같이 분류하였다.

이 Table에서 알 수 있듯이 제품 아이덴티티의 구성요소 는 다양한 분야에 걸쳐 있어 체계적으로 범주화하기는 매우 어렵다. 단순히 제품의 내부, 외부를 디자인하는 것이 아니 라 기업과 브랜드의 개념을 보여주는 추상적이고 무형적인 요소와 제품의 직접적인 기능을 보여주는 구체적이고 유형

Table 2. Structure of product Identity total management elements

\begin{tabular}{|c|c|c|c|c|}
\hline \multicolumn{2}{|c|}{ Category } & Content & \multicolumn{2}{|l|}{ Characteristic } \\
\hline \multirow{4}{*}{$\begin{array}{l}\text { Entire } \\
\text { company }\end{array}$} & \multirow{4}{*}{ Intangible } & $\begin{array}{l}\text { - Corporate ideology } \\
\text { - Design philosophy }\end{array}$ & \multicolumn{2}{|l|}{ Do not easily change and present the highest philosophy } \\
\hline & & $\begin{array}{l}\text { - Technical component } \\
\text { - Marketing component } \\
\text { - PR component }\end{array}$ & \multicolumn{2}{|c|}{$\begin{array}{l}\text { Elements that change according to the changes in technology, life-style } \\
\text { and product/market situation } \\
\text { Present a new product concept }\end{array}$} \\
\hline & & $\begin{array}{l}\text { - Operational method } \\
\text { - User interface }\end{array}$ & $\begin{array}{l}\text { Tangible external appearance is determined at times } \\
\text { through the intangibly determined operational method }\end{array}$ & \multirow[b]{2}{*}{ Product related } \\
\hline & & $\begin{array}{l}\text { - External appearance shape } \\
\text { - Manufacturing quality } \\
\text { - Color, shape, font, logo }\end{array}$ & $\begin{array}{l}\text { External appearance styling aspect } \\
\text { Product manufacturing / production aspect } \\
\text { CI system application aspect }\end{array}$ & \\
\hline \multirow{3}{*}{$\begin{array}{l}\text { Particular } \\
\text { product }\end{array}$} & \multirow{3}{*}{ Tangible } & $\begin{array}{l}\text { - Store } \\
\text { - Package } \\
\text { - Product manual }\end{array}$ & \multicolumn{2}{|l|}{$\begin{array}{l}\text { Product purchase time aspect } \\
\text { Product purchase / shipping aspect } \\
\text { Product purchase / usage aspect }\end{array}$} \\
\hline & & - Product characteristics aspect & \multicolumn{2}{|c|}{$\begin{array}{l}\text { Related to the special details that arise according to particular product } \\
\text { (group) when the company produces various products }\end{array}$} \\
\hline & & $\begin{array}{l}\text { - Operational method } \\
\text { - User interface }\end{array}$ & \multicolumn{2}{|c|}{ Related to the special details applied only to particular product } \\
\hline
\end{tabular}


적인 요소들을 함께 담아야 하고 차별화되지만 동질적인 느 낌을 함께 내포해야 하는 모순성 등 관리를 위해 고려해야 하는 요소가 복잡하게 얽혀있기 때문이다. 국내 기업은 개념 적인(Conceptual) 구성요소와 실체적인(Practical) 구성요 소, 양쪽 모두 관련된 상관(Relative) 요소를 모두 사용하여 제품 아이덴티티를 구축, 관리하는데 적용하고 있다.

\subsection{Service identity}

기업들은 그 동안 다양한 마케팅 활동, 제품에 대한 서비 스 지원, 고객과의 커뮤니케이션을 통해 서비스품질을 향상 시켜왔고 많은 성과도 거두었다. 하지만 서비스산업의 경쟁 화 가속으로 고객경험관리의 일관성과 자사만의 차별화된 서비스 경험을 통합적으로 고객에게 제공할 수 있는 장기적 인 전략 구축이 요구되었고 기업들은 빠르게 이런 일련의 서 비스들을 기업의 정체성을 나타내는 한 요소로 만드는 작업 에 착수하고 있는데 그것이 서비스 아이덴티티다. 학문의 성 격 상 실무 쪽의 빠른 움직임과 달리 학계에서의 서비스 아 이덴티티에 대한 구체적인 정의는 아직 없는데 기업 아이덴 티티, 브랜드 아이덴티티, 제품 아이덴티티 개념적 정의 도 출 시 적용한 이론들로 유추해 보면 서비스 아이덴티티는 기업이 고객에게 제공하길 원하는 서비스의 가치와 의미를 서비스측면에서 일관성 있게 전달하여 형성된 연상들로 자 사만의 서비스 통합 전략이라 할 수 있다.

목표하는 내부인력에 대한 외부의 평가 및 결과, 여러 고 객경험관리 활동을 통해 축적된 서비스 가치의 가시화, 기업 이 서비스를 통해 이루려 하는 기업의 이미지 도출 등 서비 스 아이덴티티 형성에 필요한 여러 목표들과 활동들의 선별 작업은 기업의 서비스 아이덴티티 구축에 선행되어야 하는 작업들이다.

또한 서비스의 특징 상 생산과 소비가 일어나려면 제공자 와 소비자의 상호작용을 필수이며 직접적으로 제공자와 소 비자가 대면을 하지 않는 상황에서도 서비스를 마치기 위해 프로세스 상에 존재하는 모든 이해관계자들은 서비스 아이 덴티티의 개념 정립 시 간과되지 말아야 하는 주요 핵심 구 성요소가 될 수 있다.

\section{Identity Framework}

\subsection{Service-oriented corporate identity framework}

다양한 기업환경의 변화에 따라 시장에서 나타나는 기업, 브랜드, 제품 아이덴티티에 대한 인식이나 가치의 변화는 지 속적으로 일어나고 있지만 기업의 핵심 철학을 담은 기업
아이덴티티, 기업 아이덴티티를 브랜드 차원에서 적용한 브 랜드 아이덴티티, 브랜드 아이덴티티를 가시적이고 구체적으 로 풀어낸 제품 아이덴티티에 대한 근본적인 정의와 가치는 크게 달라진 게 없다. 이것은 바꾸어 말하자면 기업, 브랜드, 제품은 성장, 변화, 트렌드에 따라 스타일을 조금 달리할 수 는 있으나 변하지 않는 가치는 소유하고 있어야 한다는 것이 다. 기술의 급속한 발전과 서비스산업화로 기업의 생존경쟁 이 더욱 치열해지고 있다. 기술과 서비스에서 가치가 판가름 나고 인간의 창의성과 감성가치에 기반을 둔 제품들이 쏟아 져 나오고 있다. 이러한 발전들은 소비자의 라이프 스타일과 구매기준을 변화시키고 있고 기업이미지 전략은 어느 시대 보다 중요해졌다. 그러나 추상적이고 무형적인 기업과 브랜 드의 가치를 제품에 반영하여 외형적으로, 시각적으로 전달 하는 방법은 대부분의 기업들이 시도한 방법들로 이미 포화 상태이다. 또한 무형적인 가치를 제품에 담아 동일성은 유지 하되 트렌드에 맞게 변화하고 자사만의 차별성을 함께 가져 가려는 기업들의 욕심은 오히려 시장에서 제품의 차별성을 더 떨어뜨리는 결과를 가져왔다. 즉 기업과 브랜드 아이덴티 티가 추구하는 이념과 가치들이 제품을 통해 모두 가시화되 긴 힘들고, 제품에 너무 많은 의미와 가치를 부여하다 보니 혼돈이 생겨나게 되었다. 물론 기업들은 그 동안 많은 부분 을 고객만족, 고객경험관리 형태로 브랜드와 제품이 모두 감 싸 안을 수 없었던 간극을 메우려 노력해 왔고 서비스에 대 한 부분을 완전히 배제하고 아이덴티티를 구축해 온 것은 아 니다. 그러나 많은 기업들이 그 동안 서비스를 제품의 구매 로 연결하는 부가적인 요소로만 인지하여 서비스 프로세스 상의 파생되는 수 많은 요소들을 간과하여 왔다. 이제 기업 은 시대의 요구에 맞게 서비스를 제품이 표출하기 힘들었던 기업과 브랜드의 여러 무형적인 가치들을 담아 일관적으로 반영하는 하나의 중심 아이덴티티로 발전시켜 나아가야 한다.

따라서 본 연구에서는 서비스 아이덴티티 중심으로 새로 운 기업 아이덴티티를 재구축하고 가치를 산출해 내는 것이 기업들이 앞으로 견지해야 할 가장 중요한 아이덴티티 방법 론이라 하겠다. 그 동안 선행 연구되어온 기업 아이덴티티와 브랜드 아이덴티티의 정의와 구성요소를 다시 살펴보면 크 게 무형적(추상적)요소와 유형적(구체적, 시각적)요소로 나 뉜다, 하지만 기업과 브랜드를 담아 구체적으로 보여줄 수 있는 시각적이고 물질적인 요소는 제품과 이미지 요소 등으 로 많이 제한적이다(물론 오너쉽(Ownership), 조직, 마케팅, 이벤트, $\mathrm{PR}$ 등 기업의 여러 활동을 통해 생산되는 유형적인 요소들도 있지만 일반적으로 제품과 심볼 등을 대표적 유형 요소로 간주한다). 기업과 브랜드 아이덴티티를 구성하는 요 소 중에 무형적인 요소가 유형적인 요소보다 훨씬 더 많은 부분을 차지하고 있음에도 불구하고 지금까지 실체적인 요 소들을 위주로 커뮤니케이션이 이루어진 이유는 개념적인 
요소들을 소비자에게 전달하여 인식을 시킨다는 일이 매우 복잡하고 어려운 작업이며 많은 시간이 소요되기 때문이다. 하지만 산업 패러다임의 변화로 서비스업을 수행하는 기업 들을 더 많이 생성하고 제조기업들도 서비스를 제품화하는 일이 늘어나면서 더 이상 브랜드와 제품만으로 기업의 아 이덴티티를 대표할 수 없게 되었다. 심지어 많은 기업들이 무형적인 가치로 측정이 어렵다 생각된 서비스로 기업, 브 랜드 심지어 제품이 가졌던 개념적(Conceptual)이고 상관 적(Relative) 요소들을 가시화하여 풀어내고 있다.

이에 Figure 2와 같이 서비스 아이덴티티를 추가한 통합 기업 아이덴티티의 새로운 프레임워크를 만들고 서비스를 구조적으로 아이덴티티화 하는 방법을 함께 제시해본다.

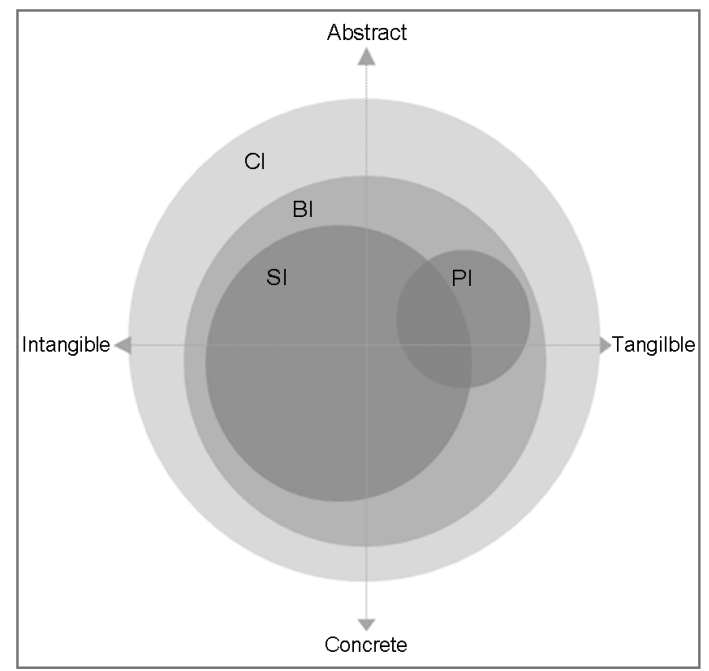

Figure 2. Service-oriented corporate identity framework

\subsection{Service identity structure system}

위에서 언급했듯 그 동안 서비스 활동을 아이덴티티라는 개념으로 묶어 발전시키기 어려웠던 것은 첫째, 서비스라는 속성이 가지는 무형성과 측정이 어렵고 잡아내기 어려운 여 러 과정을 포함하고 있기 때문이고, 둘째, 서비스는 기업 아 이덴티티, 브랜드 아이덴티티, 제품 아이덴티티의 수많은 유, 무형적(추상적, 구체적) 요소들과 얽혀 있어 분류가 매우 복 잡하기 때문이다. 또한 기업의 성격도 서비스를 주 제품으로 제공하는(Service-driven) 기업과 제품과 서비스를 하나의 제품으로 제공하는 기업, 제품에서 서비스로 비즈니스 포트 폴리오를 옮기고 있는 기업 등 기업의 서비스를 자사의 제 품으로 이용하는 비율이 모두 다르기 때문에 일관적으로 분 류하여 표준화된 구조에 넣는 작업은 매우 어렵다 하겠다. 하지만 서비스의 성격을 규정짓는 작업들은 계속 이어지고
있는데 Kotler(2001)는 서비스의 특성을 아래의 4가지로 분류했다.

- 형태가 없으며(무형성)

- 없어지기 쉽고(소멸성)

- 생산과 소비가 분리되지 않으며(비분리성)

- 쉽게 변한다(변이성)

이 4 가지의 특성은 서비스의 성질을 이해하고 관찰하여 구체화 시키는데 많은 도움이 된다. 이 4 가지 특성에 기업, 브랜드, 제품 아이덴티티의 구성요소들과 함께 분류하여 무 형을 유형에서 가시화 해볼 수 있는데 (1) 무형의 가치를 외형의 서비스(제품 또는 서비스품목)로 발전시키고 (2) 소 멸성 강한 사용자의 경험 등을 공정(단계)화하여 이 과정 안에서 소비자의 경험이나 만족도를 높일 수 있는 방법론 찾 고 (3) 조직의 서비스나 제품, 품질이 고객과 만나는 접점들 (Moment of Truth)을 추출하여 상품화하고 (4) 쉽게 변이 될 수 있는 인재의 질이나 제품 편익 등을 일관화하는 것들 이 바로 그것들이다. 즉 기업, 브랜드, 제품 아이덴티티의 무 형성을 가시화하고, 소멸성을 공정(단계) 화하고, 비분리성의 접점을 추출하여 상품화하고, 변이성을 일관화하여 서비스를 향상, 확장시키고 이 과정을 계속 반복을 하다 보면 일정 기 간 후 그 기업이 추구하는 서비스 아이덴티티 핵심요소들을 추출할 수 있다. 이 요소들로 타 기업과 차별화된 서비스 아 이덴티티 구축은 물론 그 서비스 아이덴티티를 중심으로 새 로운 기업의 통합 아이덴티티 방법론이 제시될 수 있다.

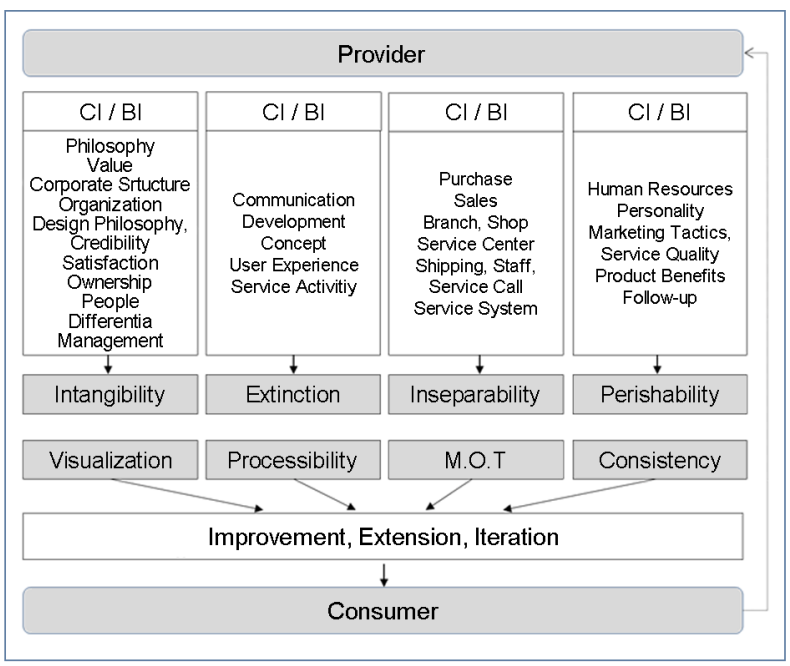

Figure 3. Service identity structure system 


\section{Case Study}

영국의 버진 그룹(Virgin Group)의 계열사인 버진 아틀란 틱(Virgin Atlantic) 항공은 타 항공사와 차별성을 가지며 버진 아틀란틱만의 고유한 기업 정체성 전략에 서비스가 어 떠한 효과를 발휘하는지 잘 보여주는 사례로서 버진 아틀란 틱 항공이 고객을 위해 서비스로 풀어낸 두 가지 사례를 통 해 본 연구에서 제안한 프레임워크와 서비스 구조시스템을 살펴보고자 한다. 버진 아틀란틱 항공이 제공하는 도어 투 도어 서비스(Door to Door Service). 퍼스트와 비즈니스 클래스를 이용하는 고객들을 타깃으로 한 이 서비스는 고객 이 항공 일정을 예약하는 동시에 시작된다. 집 또는 목적지 에서 공항까지 무료 쇼퍼(chauffer: 기사가 모는 리무진) 서비스는 물론 개인 수행원이 항공권 체크인과 수화물 처리 까지 알아서 해결해 준다. 또한 기내에서 먹을 음식과 사용 하는 제품에 대한 선택이 가능하고 도착지에 내려서도 똑같 은 절차를 거쳐 고객이 원하는 목적지에 도착해서야 비로서 서비스는 종결된다. 또 다른 성공사례는 2008년 히드로 공 항의 터미널3에 버진 아틀란틱 항공만의 전용 공간을 디자 인하게 된 사례로 기존에 행해지는 공간디자인 범위에서 벗 어나 그 공간을 이용하는 승객들의 모든 여정을 시각화하여 실제적인 서비스의 모습을 관찰하고 고객의 경험을 개선하 였다. 핵심적 개선사항은 다음과 같은데. 첫째, 체크인 시간 을 최소화하였다. 탑승객의 대부분이 이코노미 클래스인 만 큼 이코노미 클래스는 쉽게 지체되는 것으로 조사되었다. 체크인시 시간을 최소화하기 위해 무인 탑승처리 시스템 (kiosks desk)를 추가적으로 설치하고 즉시 수하물 무게를 달아보고 추가요금을 처리할 수 있는 저울을 설치함으로써 사용자의 이동경로를 대폭 줄이게 된다. 둘째, 버진의 독특 한 드라이브 쓰루 체크인(Drive-thru Check-in: 차에서 내리지 않고 체크인을 먼저하고 차를 파킹 하는 방법)과, 리 모 체크인(Limo Check-in: 리무진을 타고 터미널에 도착 시 직원이 미리 탑승표를 준비해 기다림으로써 소요시간을 줄일 수 있게 하는 서비스). 셋째, 맞춤식 서비스를 실현할 많은 아이디어들이 고안하였다. 각 아이디어는 승객의 이동 경로를 기준으로 각 단계별로 배치될 직원 수, 배치될 위치, 서비스 방침, 업무 인수인계 방법, 비즈니스 및 퍼스트클래 스 승객을 위한 라운지 이용법 등 다양한 형태로 직원들 전 부가 공유해야 할 지침으로 구체화됨으로써 서비스가 표준 화될 수 있도록 하였다(Yoon, 2011).

독일에 본사를 둔 유럽 1위 시장조사기관 G라의 2008년 3-4월 소비자조사 결과에 따르면 터미널이 오픈된 지 4달 만에 장거리 탑승객 수가 $4 \%$ 증가하였고 비즈니스, 퍼스트 클래스 탑승객은 $10 \%$ 까지 증가하였다. 고객 대상 만족도
설문에서 $90 \%$ 의 만족도를 얻었으며, 전체적으로 터미널3의 서비스 만족도는 $89 \%$ 를 얻었다. 이 사례들을 통해 보면 그 동안의 버진 그룹의 기업 아이덴티티가 추구했던 혁신, 도전, 시도라는 기업 가치를 버진 항공사의 제품(비행기 항공권 구매 + 공항 서비스 + 비행기 탑승)의 고객경험 향상(서비 스의 향상)을 통해 구축하려 하였는데 이는 항공권을 파는 제품의 목적을 공항 이용 전, 공항 이용 시, 탑승 후, 도착 후 목적지로 이동하는 서비스 범위로 확장하여 항공권과 서 비스이라는 복합적인 제품을 파는데 제한적일 수밖에 없는 제품 아이덴티티의 실제 대입 한계를 서비스 아이덴티티로 풀어내었다라고 볼 수 있다.

종합하여 보면 위의 모든 경로의 고객 경험들을 가시화, 공정 (단계) 화, 접점 서비스의 상품화, 일관화하여 서비스를 향상시킬 방법을 추출, 적용하니 그것들이 고객경험 향상으 로 이어지고 그 요소들이 서비스 아이덴티티는 물론 기업의 통합 아이덴티티의 구성요소와도 일맥상통하여 변화의 시기 에 기업에겐 경쟁력 강화의 방법으로, 고객에게는 차별화된 기업 철학을 전달할 수 있어 서비스 아이덴티티 중심의 기업 아이덴티티 재 구축이 선행되어야 할 것이다.

\section{Conclusion and Discussion}

본 연구는 서비스산업화에 따른 산업 패러다임의 변화에 서비스를 아이덴티티화 하여 기업 아이덴티티의 하부 아이 덴티티로 새롭게 규정하고 개념적인 정의를 정립해보고 서 비스의 4 가지 특성으로 서비스 아이덴티티의 구조시스템을 제안하여 서비스를 보다 가시화, 구체화 할 수 있는 방법을 제시해 보았다. 또한 버진 아틀란틱의 서비스 디자인 사례를 통해 서비스 아이덴티티의 범위와 역할을 살펴보고 이를 통 한 기업이미지 전략에 새로운 방향성을 논의했다. 그러나 서 비스 아이덴티티에 대한 학문적인 연구는 충분하게 논의되 지 않고 있어 본 논문과 같은 연구들을 통한 서비스 아이덴 티티에 대한 지속적인 논의는 필요하다.

추후로 여러 기업들의 비즈니스 사례 분석을 통해 시대의 변화에 따라 생성, 파생, 소멸되는 여러 하부 아이덴티티들 의 관계 정립과 서비스 중심의 서비스 아이덴티티를 구조화 하여 서비스 아이덴티티 중심의 기업 아이덴티티의 가치 인 식 변화와 확장성에 대한 연구가 지속되어야 할 것이다. 


\section{Acknowledgements}

This work was funded by grants from Korean Federation of Science and Technology Societies (Grant-\#KFSTS0000000).

\section{References}

Aaker, D.A., Building Strong Brands, The Free Press (pp.79), New York, NY, 1996.

Alessandri, S. W., Modeling corporate identity: a concept explication and theoretical explanation. Corporate Communications Vol.6 No.4 (pp173-182) New York, NY 2001.

Hyojin, M. and Gabshin, H., The Relations between Corporate Visual Identity, Identification, and Corporate Reputation: Focused on Mobile Telecom Company(pp.23) 2008.

Haejin, C. and Jisung, S., Research Reports: A Study on Establishing Strong Brand Identity by Building Visual Identity of a Product Interface, The Korean Society of Design Culture,Vol.12 No.2(pp.124-134), 2006.

Inhyuk, C. and Hwadong, K., Elements of Corporate Identity in a Competitive Value Perspective, Korean Academic Society of Business Administration Vol.29 No3.(pp.429-450), 2000.

Philip, K., A framework for Marketing Management. New Jersy(US) Prentice-Hall, 1992.

Seongwon, Y., Background of Service Design http:/usableweb.co.kr/ (Retrieved June 24, 2011).

Seongwon, Y., Overseas Case, become the new engine of Virgin Atlantic Airways. Engine Service Design, http://cafe.naver.com/usable/795 (Retrieved October 06, 2010).

Sonil, K., The Effects of Brand Portfolio Characteristics and Corporate Image on Consumer Evaluations of Brand Extensions, The Hanyang journal of economic studies Vol.19 No.2, 1998.
Sunwoo, A. and Joomyung, R., Structure and Managing Strategy of Design Identity Program Journal of Korean society of design science Vol.23 No.1 (pp.269), 2010.

Taesook, L., A study on the corporate product identity management 1998. Yougnran, B., A study of Brand management Efficiency through Brand Identity, Korea Digital Design Council, Vol.12 No.(pp.221-229), 2006.

Wangmi, S., A study on Evaluation Framework of Coherence Experience on Interactive Product 2011.

\section{Author listings}

Hwasun Kang: 73dadada@gmail.com

Highest degree: MS in Communications Design with an emphasis in Digital Design, Pratt Institute N.Y.

Position title: Student (Researcher) $2^{\text {nd }}$ Semester in PhD Program, Interaction Design, Graduate School of Techno Design, Kookmin University

Areas of interest: Service Design, Service Identity, Interaction Design

Younghwan Pan: peterpan@kookmin.ac.kr

Highest degree: PhD, Department of Industrial Engineering, KAIST Position title: Assistant Professor, Department of Interaction Design, Graduate School of Techno Design, Kookmin University Areas of interest: User Experience Strategy, Service Design, Interaction Design

Date Received : 2012-01-05

Date Revised : 2012-01-10

Date Accepted : 2012-01-26 